\title{
BMJ Open Weekly miscarriage rates in a community-based prospective cohort study in rural western Kenya
}

\author{
Stephanie Dellicour, ${ }^{1}$ George Aol, ${ }^{2}$ Peter Ouma, ${ }^{2}$ Nicole Yan, ${ }^{1}$ Godfrey Bigogo, ${ }^{2}$ \\ Mary J Hamel, ${ }^{3}$ Deron C Burton, ${ }^{3}$ Martina Oneko, ${ }^{2}$ Robert F Breiman, ${ }^{4}$ \\ Laurence Slutsker, ${ }^{3}$ Daniel Feikin, ${ }^{3}$ Simon Kariuki, ${ }^{2}$ Frank Odhiambo, ${ }^{2}$ \\ Gregory Calip, ${ }^{5}$ Andreas Stergachis, ${ }^{6}$ Kayla F Laserson, ${ }^{3}$ Feiko O ter Kuile, ${ }^{1}$ \\ Meghna Desai ${ }^{3}$
}

To cite: Dellicour S, Aol G, Ouma $\mathrm{P}$, et al. Weekly miscarriage rates in a community-based prospective cohort study in rural western Kenya. $B M J$ Open 2016;6:e011088. doi:10.1136/bmjopen-2016011088

- Prepublication history for this paper is available online. To view these files please visit the journal online (http://dx.doi.org/10.1136/ bmjopen-2016-011088).

Received 11 January 2016 Revised 8 March 2016 Accepted 22 March 2016

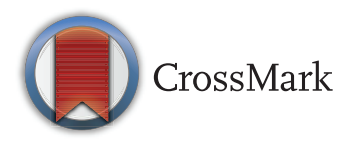

For numbered affiliations see end of article.

\section{Correspondence to} Dr Stephanie Dellicour; stephanie.dellicour@|stmed. ac.uk

\section{ABSTRACT}

Objective: Information on adverse pregnancy outcomes is important to monitor the impact of public health interventions. Miscarriage is a challenging end point to ascertain and there is scarce information on its rate in low-income countries. The objective was to estimate the background rate and cumulative probability of miscarriage in rural western Kenya. Design: This was a population-based prospective cohort.

Participants and setting: Women of childbearing age were followed prospectively to identify pregnancies and ascertain their outcomes in Siaya County, western Kenya. The cohort study was carried out in 33 adjacent villages under health and demographic surveillance.

Outcome measure: Miscarriage.

Results: Between 2011 and 2013, among 5536 women of childbearing age, 1453 pregnancies were detected and 1134 were included in the analysis. The cumulative probability was $18.9 \%$. The weekly miscarriage rate declined steadily with increasing gestation until approximately 20 weeks. Known risk factors for miscarriage such as maternal age, gravidity, occupation, household wealth and HIV infection were confirmed.

Conclusions: This is the first report of weekly miscarriage rates in a rural African setting in the context of high HIV and malaria prevalence. Future studies should consider the involvement of community health workers to identify the pregnancy cohort of early gestation for better data on the actual number of pregnancies and the assessment of miscarriage.

\section{BACKGROUND}

Miscarriage is the most common adverse pregnancy outcome with aggravating emotional consequences for affected individuals and families. It is also a critical indicator of embryotoxicity and an important outcome for the study of embryotoxic effects of

\section{Strengths and limitations of this study}

- This study identified pregnancies early from the general population in a rural setting in western Kenya and refusal rate was low (6\%).

- The study is strengthened by the use of survival analysis with left truncation and the life table method to estimate weekly background rates and cumulative probability of miscarriage, respectively.

- Misclassification between spontaneous and induced abortion cannot be ruled out, which is a limitation of the present study. Given estimates were within the expected range, and since known risk factors for miscarriages could be confirmed, this is unlikely to have had a substantial effect on the estimates.

- Estimates for the rate of miscarriage in early weeks of gestation were less precise due to the low numbers of pregnancies detected $<6$ weeks gestation.

environmental, occupational and medication risks. ${ }^{1-3}$ Furthermore, it is a relevant end point to track the progress of reproductive health programmes and their impact on maternal health. Without accounting for miscarriage, maternal and reproductive healthrelated indicators miss a significant number of unreported pregnancies that are often not seen by the health system and are not recorded. For instance, indicators for antenatal care (ANC) coverage are based on the total number of women who had a live birth in a specific time period not accounting for up to $30 \%$ of pregnancies that are lost either to miscarriage or stillbirth. ${ }^{4}$ This may lead to unrepresentative estimates of access and utilisation of healthcare for high-risk pregnancies ending in miscarriage or stillbirth. 
Despite this being a significant reproductive health outcome, data on miscarriage rates in low-income and middle-income countries are scarce. Studies from industrialised countries report rates of miscarriage in clinically recognised pregnancies (ie, from 5 to 6 gestational weeks following the last menstrual period (LMP), the common gestational age for pregnancy recognition) that vary between $11 \%$ and $22 \% .^{6-9}$ When taking into account early miscarriage for pregnancies diagnosed by human chorionic gonadotropin or ultrasound before the appearance of fetal heart activity, the reported rates are closer to $30 \%{ }^{7}$

Miscarriage is a challenging end point to ascertain and accurate rates of miscarriage are difficult to estimate. There are methodological complexities of conducting studies to assess the miscarriage rate ${ }^{10}$ which relate to the difficulties in identifying a representative sample of pregnancies at the time of conception, the confirmation of suspected pregnancy and the determination of the exact timing of pregnancy loss. To accurately capture all pregnancy losses in a population, a study needs to be able to identify pregnancies from the time of conception and follow them prospectively. Early pregnancy losses, which occur before a pregnancy is usually recognised (ie, <5-6 weeks gestation), can only be detected by frequently repeated highly sensitive pregnancy tests.

Few studies have been designed to detect such early pregnancy loss and ascertained pregnancies close to the time of conception by enrolling participants who are planning to conceive and consent to regular pregnancy tests. $^{7-9}{ }^{11-13}$ Since a significant proportion of pregnancies are unplanned, ${ }^{14}$ data from these studies may have limited generalisability. Other studies recruiting women from antenatal clinics miss pregnancy loss occurring before initiation of ANC and may also be prone to selection bias as women presenting early for ANC may represent higher risk pregnancies than women presenting later. ${ }^{15}$ The assigned timing of miscarriage is usually based on the time of clinical recognition of pregnancy loss; however, fetal death may have occurred weeks before. $^{16}$

Studies of miscarriage in low-income and middle-income countries face additional challenges as most miscarriages occur without any contact with the formal healthcare system and are not registered. Since pregnant women usually present for ANC late in pregnancy (with an estimated 11-54\% of women initiating ANC in the first trimester ${ }^{17-19}$ and most presenting late in the second trimester), health facility-based recruitment and data collection strategies are inappropriate. In such settings, the study of miscarriage requires a community-based approach taking into account the different cultural and superstitious beliefs that may affect pregnancy disclosure and detection. ${ }^{19-21}$ Furthermore, reliable data on gestational age are difficult to obtain as ultrasound scans are rarely available and date of LMP may not be reliable in settings with limited literacy. ${ }^{22} 23$
There is also a higher risk of misclassification of induced abortions as spontaneous abortions as the former are illegal in most of these settings. The methodological constraints for measuring this outcome require early pregnancy detection and prospective follow-up from a population-based representative sample of all women of childbearing age (WOCBA) to minimise selection bias. There are no published data on such studies in lowincome countries. The study presented here describes the rate of miscarriage and associated risk factors in a community-based prospective cohort study of WOCBA in rural western Kenya.

\section{METHODS}

\section{Overview of study design}

A prospective cohort of pregnant women was enrolled within a pharmacovigilance study to assess the risk of inadvertent first trimester exposures to artemisinin combination therapy (being reported elsewhere ${ }^{24}$ ) between February 2011 and February 2013. Pregnancies were identified as early as possible through health facility and community-based strategies (described below), and followed prospectively (ie, before the pregnancy outcome was known) to document pregnancy outcome.

\section{Study site}

The study area was located in Siaya County, lying northeast of Lake Victoria in Nyanza Province, western Kenya. The cohort study was carried out in 33 adjacent villages under the Kenya Medical Research Institute-Centers for Disease Control and Prevention (KEMRI-CDC) Health and Demographic Surveillance System area $\left(\right.$ KEMRI-CDC HDSS $^{25}$ ). Nyanza Province has a high burden of disease and health indicators that are worse than the overall Kenyan national statistics. ${ }^{26}$ Malaria transmission is high with parasitaemia of $20 \%$ in over 14-year-olds (unpublished KEMRI/CDC data for 2010). Whereas the national HIV prevalence is $6.3 \%$ (4\% for men and $8 \%$ for women), the prevalence for Nyanza Province is close to double, around $14 \%$ ( $11 \%$ for men and $16 \%$ for women). ${ }^{27}$ The total fertility rate in the area was 5.4 and around a third of currently married women aged 15-49 years used a modern contraceptive method according to a health and demographic survey in 2008-2009. ${ }^{26}$

\section{Community mobilisation and formative research}

The acceptability of community-based pregnancy testing was unknown but important for this study. Community mobilisation activities included a series of meetings over several months with the District Medical Officer for Health, village chiefs, district officers and counsellors; the community advisory board was set up by KEMRI-CDC and community members to introduce and get feedback on the proposed study plans. 'Baraza' (community meetings) were held in all 33 villages within the study area. Study brochures were also distributed 
through the community meetings and at the central health facility. Formative research involving 10 focus group discussions was carried out with the aim of exploring the sociocultural context around pregnancy and to investigate the acceptability of proposed study procedures (reported elsewhere ${ }^{28} 29$ ).

\section{Recruitment of WOCBA and pregnancy detection}

Following community mobilisation, door-to-door enrolment was carried out to inform eligible WOCBA. All women aged 15-49 years, resident in households within the defined HDSS catchment area and participating in a population-based disease surveillance project (PBIDS), ${ }^{30}{ }^{31}$ were eligible for enrolment. Women were excluded if they refused to participate, were unable to provide informed consent due to mental, physical or social inability or if they refused to be followed up to the end of pregnancy. Enrolment was active throughout the study period whereby newly eligible women (who turned 15 years of age during the study period or in-migrant joining PBIDS) were invited to join the study.

WOCBA who consented to participate were asked if they might be pregnant and offered a pregnancy test at the time of enrolment if they were not visibly pregnant and again approximately every 3 months from October 2011 onwards by village-based community interviewers. Any participant with a detected pregnancy was referred to the antenatal clinic at the referral health facility, Lwak Hospital, where trained study nurses confirmed the pregnancy through ultrasound or examination and auscultation for gestations $>24$ weeks and offered free ANC. Additionally, all pregnant patients presenting at Lwak Hospital ANC were assessed for study eligibility by a study nurse and enrolled if all selection criteria were met.

\section{Gestational age assessment}

Gestational age was assessed using multiple methods, including ultrasound scans at the first antenatal visit at Lwak ANC (for participants presenting before 24 weeks); reported first day of LMP; reported gestational age at the time of pregnancy loss; Ballard scoring for live births captured within 3 days of delivery; ${ }^{32}$ and fundal height measurements recorded at ANC. Not all methods were available for all pregnancies since some were not seen at ANC (no fundal height or ultrasound measurement available) or were seen at ANC but beyond 24 weeks. The Ballard score was only available for live births seen within 3 days of delivery. Furthermore, some participants could not recall their LMP or, in some instances, had not resumed their menses since their previous pregnancy. For this analysis, gestational age was determined using the most accurate measurement available for each participant. Methods in order of decreasing accuracy were: ultrasound scan taken before 24 weeks gestation, Ballard estimates, LMP or reported gestation at time of pregnancy loss and lastly gestational age derived from fundal height assessment.

\section{Risk factors}

Obstetric history and ANC laboratory information collected routinely at antenatal booking (haemoglobin level, HIV and syphilis testing, and malaria microscopy) were extracted from the ANC records at Lwak Hospital or antenatal cards by study nurses. Demographic characteristics were collected through interviews at ANC or at the time of pregnancy outcome follow-up if the participant was not seen at ANC. Household-level wealth quintiles were obtained from data collected routinely through the HDSS (such as occupation of household head, primary source of drinking water, use of cooking fuel, in-house assets (eg, radio and television) and livestock), which were calculated as a weighted average using multiple correspondence analysis. ${ }^{33}$

\section{Pregnancy outcome}

Pregnancy outcomes were assessed using a combination of health facility and home-based follow-ups. The latter is particularly relevant for miscarriages, because the vast majority of these events occur in the community and not in the health facilities. Village-based staff received monthly lists of participants with estimated delivery dates in their respective catchment area. Study nurses were notified of pregnancy outcomes by village-based staff and follow-ups were carried out either at home or at the health facility. A detailed structured questionnaire about the delivery and outcome was administered face to face. Pregnancy outcomes captured included pregnancy losses (miscarriages, induced abortions and stillbirths), live births and major congenital malformations detectable at birth by surface examination. We defined miscarriage, also called spontaneous abortion, as a pregnancy that ends spontaneously before 28 weeks gestation as per the WHO definition of fetus viability. ${ }^{34}$ A fetal death after viable gestational age is defined as a stillbirth.

\section{Data analysis}

Analyses were performed using Stata V.12.1 (StataCorp LP, College Station, Texas, USA). Survival analysis with left truncation was used to estimate the miscarriage rate by gestational week to account for delayed pregnancy detection and the range in gestational ages at the time of pregnancy detection. Crude rate estimates (ie, dividing the number of miscarriages by the total number of pregnancies under study) are appropriate when it is possible to detect and enrol pregnancies from the time of conception. Most miscarriages occur early in pregnancy prior to clinical detection of pregnancy; ${ }^{35}$ the rapidly decreasing risk of miscarriage across the first trimester of pregnancy highlights the influence of gestational weeks at time of pregnancy detection in study or programme settings on the estimated miscarriage rates. Therefore, rate estimates should account for left 
truncation (early pregnancy) and, as far as it is possible, for the actual number of pregnancies under observation at each specific gestational week. ${ }^{15} 36{ }^{37}$ Left truncation was used to account for survival bias as the average gestational age that pregnancies were detected was around 13 weeks and only pregnancies that survived the early weeks of gestation (the highest risk of miscarriage) were followed prospectively. ${ }^{36}$ The life table methods were used to calculate the cumulative probability of survival and cumulative probability of miscarriage. Standard methods were used to calculate probability of miscarriage by gestational week. ${ }^{6}$ In brief, the miscarriage rate during the specific week of gestation was converted to probability using the formula: (miscarriage rate)/(1+ $($ miscarriage rate $\times 0.5))$. The remaining risk of miscarriage by gestational week was calculated by subtracting the probability of surviving the remaining weeks from 1. The probability of fetal survival during the remaining weeks was the product of the probability of survival for week $\times$ and the probability of survival for week $x+1$. Cox proportional hazard regression models with left truncation were fitted to estimate the effect of risk factors on miscarriage. $^{36}$

Figure 1 Study participant flow diagram from screening to inclusion in data analysis for miscarriage. GA, gestational age.
Ethical review and consent

Written informed consent or assent was obtained from each participant including consent to linking individual data to PBIDS and HDSS data.

\section{RESULTS}

\section{Participant enrolment and study uptake}

Between 15 February 2011 and 15 February 2013, 5536 (94\% of 5911 WOCBA approached) consented to participate and 1453 pregnancies among these women were detected; about $10 \%$ of participants were detected as pregnant at the time of enrolment. Refusal to take part in the study was low at $6 \%$ of screened participants, as were refusals to take pregnancy tests during follow-up home visits $(2 \%)$. Out of the 1453 identified pregnancies, $1134(78 \%)$ were included in the data analysis for miscarriage; 319 were excluded because pregnancy detection occurred beyond 28 weeks gestation (219) or at the time of pregnancy outcome (33), owing to lack of information on gestational age (21), loss to follow-up immediately after pregnancy detection (41), or inconsistent pregnancy end dates (5; figure 1). The 1134 pregnancies involved a total of 1079 women, 55 of whom

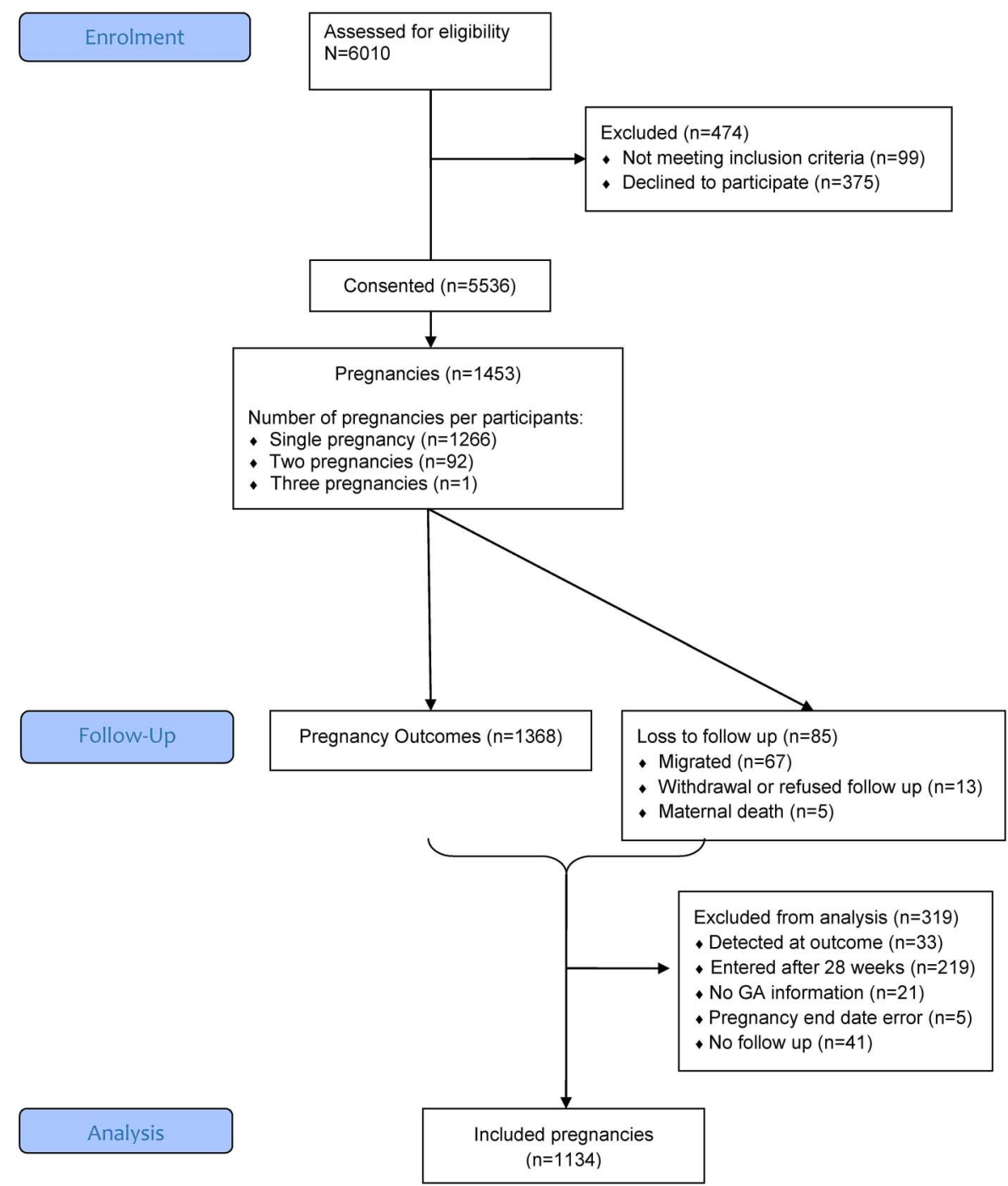




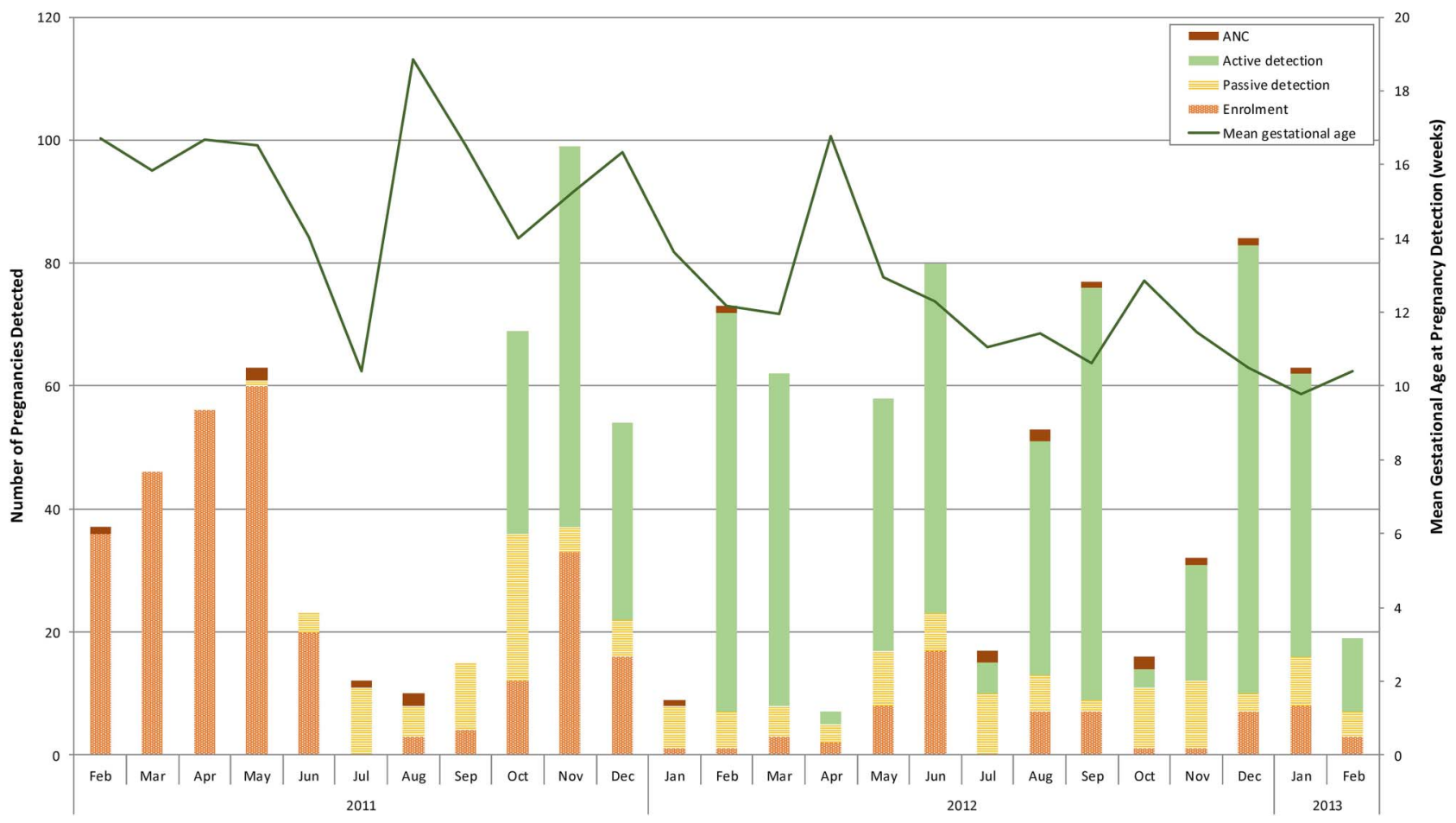

Figure 2 Number of pregnancies detected according to different recruitment strategies and mean gestational age at time of pregnancy detection over study period. Pregnancy detection strategies included: antenatal clinic at the designated study facility (antenatal care (ANC)); enrolment in the pharmacovigilance cohort study (enrolment); participant seeking pregnancy tests from study staff (passive detection) or through three monthly home visits by study staff offering pregnancy tests (active detection).

had 2 pregnancies and 1024 who had 1 pregnancy during the study period. Figure 2 depicts the number of pregnancies detected by the different strategies.

Overall, $62 \%$ of deliveries took place at a health facility, and $25 \%$ of identified miscarriages were cared for at a health facility. Sixty-seven per cent of pregnancy outcomes were captured $<1$ week after the end of pregnancy; however, for miscarriage, this proportion was only $20 \%$. The median number of days between outcome and follow-up was 3 overall (range 0-755) and 24 (range $0-602)$ for miscarriage. This reflects the fact that followups were arranged at the convenience of participants and to ensure a suitable amount of time between the event and home visit by study staff.

\section{Participant characteristics and risk factors for miscarriage}

The mean gestational age at time of pregnancy detection was 13.3 weeks (SD 6.9) and the median was 12.1 weeks. The mean gestational age at time of detection decreased over the study period with the introduction of three monthly home visits (figure 2). The mean maternal age was 26.1 years with women who miscarried being slightly older $(29.5(\mathrm{SD}=8)$ years mean age vs 25.8 $(\mathrm{SD}=7)$ years; table 1$)$. Overall, the vast majority were married $(79 \%)$ and about half of the women had completed primary education, but few had completed secondary school, with no significant difference between the groups. Farming was the main income generating activity for a higher proportion of women who miscarried compared with those with other pregnancy outcomes. There was a statistically significant difference in wealth between groups, with women who miscarried being generally poorer than those with other pregnancy outcomes (table 1). A higher proportion of miscarriage cases occurred in multigravid women with four or more pregnancies and about $25 \%$ of cases reported having a previous miscarriage (compared with 13\% for other pregnancy outcomes). Only $26 \%$ of women who miscarried had any history of ANC (compared with $98 \%$ in the other group), which may reflect the fact that most miscarriages occur before the average gestational age (21 weeks) when women initiate ANC in this area. Consequently, very few received any intermittent preventive treatment of malaria in pregnancy and an HIV test result was not available for over half of the miscarriage cases (since HIV tests are offered during the first ANC visit). However, among those with known HIV status (44), $30 \%$ of those who miscarried were HIV positive compared with $23 \%$ among those with other pregnancy outcomes.

\section{Cumulative probability of miscarriage and rate per gestational week}

There were $89(7.9 \%)$ miscarriages among the 1134 pregnancies included in the analysis. The mean gestational age at the time of miscarriage was 14.4 weeks (SD: 5.7 ) and the median was 13 weeks (range: $4.3-28$ ); $75 \%$ of miscarriages occurred by 18 weeks. The cumulative 
Table 1 Participants' characteristics and risk factors for miscarriage

\begin{tabular}{|c|c|c|c|c|c|}
\hline & Overall $(\mathrm{N}=1134)$ & $\begin{array}{l}\text { Miscarriage } \\
(\mathrm{N}=89)\end{array}$ & $\begin{array}{l}\text { Other } \\
\text { pregnancy } \\
\text { outcomes } \\
(n=1045)\end{array}$ & HR (95\% Cl) & p Values \\
\hline $\begin{array}{l}\text { Gestational age at pregnancy } \\
\text { detection in weeks (mean (SD)) }\end{array}$ & $13.3(6.9 ; 0-27.9)$ & $7.8(4.4)$ & $13.7(6.9)$ & 0.94 (0.88 to 1.01$)$ & 0.094 \\
\hline Age in years (mean (SD)) & $26.1(6.8)$ & $29.5(7.9)$ & $25.8(6.6)$ & $1.08(1.04$ to 1.11$)$ & $<0.001$ \\
\hline Age categories & & & & & $<0.001$ \\
\hline $15-20$ & $285(25.1)$ & $14(15.7)$ & 271 (25.9) & 1 & \\
\hline $21-25$ & $287(25.3)$ & $14(15.7)$ & $273(26.1)$ & $0.9(0.42$ to 1.9$)$ & \\
\hline $26-30$ & $255(22.5)$ & $16(18.0)$ & 239 (22.9) & $1.14(0.57$ to 2.3$)$ & \\
\hline $31-35$ & $179(15.8)$ & $21(23.6)$ & $158(15.1)$ & 2.31 (1.2 to 4.44$)$ & \\
\hline$>35$ & $128(11.3)$ & $24(27.0)$ & $104(10.0)$ & 4.02 (2.08 to 7.76$)$ & \\
\hline Education level & & & & & 0.713 \\
\hline None/primary not completed & $495(44.4)$ & $38(43.7)$ & 457 (44.4) & 1 & \\
\hline Primary completed & $533(47.8)$ & $44(50.6)$ & 489 (47.5) & 1.07 (0.69 to 1.66$)$ & \\
\hline Secondary completed & $88(7.9)$ & $5(5.8)$ & $83(8.1)$ & 0.69 (0.23 to 2.04$)$ & \\
\hline Missing & 18 & 2 & 16 & & \\
\hline Occupation & & & & & $<0.001$ \\
\hline Not working & $379(34.4)$ & $22(25.6)$ & $357(35.1)$ & 1 & \\
\hline Farming & 369 (33.5) & $39(45.4)$ & 330 (32.5) & $1.47(0.88$ to 2.45$)$ & \\
\hline $\begin{array}{l}\text { Small business/skilled labour/ } \\
\text { salaried }\end{array}$ & $335(30.4)$ & $19(22.1)$ & $316(31.1)$ & $0.88(0.48$ to 1.6$)$ & \\
\hline Other & $20(1.8)$ & $6(7.0)$ & $14(1.4)$ & 5.15 (2.15 to 12.34$)$ & \\
\hline Missing & 31 & 2 & 16 & & \\
\hline Marital status & & & & & 0.224 \\
\hline Single & $240(21.5)$ & $22(25.3)$ & $218(21.2)$ & 1 & \\
\hline Married & $876(78.51)$ & $65(74.7)$ & $811(78.8)$ & $0.74(0.46$ to 1.2$)$ & \\
\hline Missing & 18 & 2 & 16 & & \\
\hline Household wealth quintiles & & & & & 0.024 \\
\hline Poorest & $105(9.7)$ & $18(20.5)$ & $87(8.8)$ & 1 & \\
\hline Very poor & $158(14.6)$ & $9(10.2)$ & $149(15.0)$ & $0.33(0.15$ to 0.75$)$ & \\
\hline Poor & $220(20.4)$ & $16(18.2)$ & $204(25.6)$ & $0.4(0.2$ to 0.81$)$ & \\
\hline Less poor & 269 (24.9) & $22(25.0)$ & 247 (24.9) & $0.47(0.25$ to 0.88$)$ & \\
\hline Least poor & $328(30.4)$ & $23(26.1)$ & $305(30.8)$ & $0.39(0.21$ to 0.74$)$ & \\
\hline Missing & 54 & 1 & 53 & & \\
\hline Gravidity & & & & & $<0.001$ \\
\hline Primigravid & $219(19.6)$ & $17(19.3)$ & 202 (19.6) & 1 & \\
\hline 1-3 pregnancies & $525(47.0)$ & $23(26.1)$ & $502(48.8)$ & $0.49(0.26$ to 0.91$)$ & \\
\hline 4+ pregnancies & $374(33.5)$ & $49(55.1)$ & 325 (31.6) & 1.63 (0.95 to 2.79$)$ & \\
\hline Missing & 16 & 0 & 16 & & \\
\hline \multirow[t]{2}{*}{ Previous pregnancy loss } & $160(14.3)$ & $22(25.0)$ & $138(13.4)$ & 2.23 (1.4 to 3.56$)$ & 0.001 \\
\hline & Missing $n=17$ & Missing $n=1$ & Missing $n=16$ & & \\
\hline \multicolumn{6}{|l|}{ ANC summary } \\
\hline $\begin{array}{l}\text { Gestational age at first ANC visit in } \\
\text { weeks (mean (SD)) }\end{array}$ & $\begin{array}{l}20.8(7.8) \\
\text { range } 1.7-41.0\end{array}$ & $\begin{array}{l}10.4(4.9) \\
\text { missing } n=71\end{array}$ & $\begin{array}{l}21.0(7.7) \\
\text { missing } n=227\end{array}$ & $0.85(0.79$ to 0.91$)$ & $<0.001$ \\
\hline Number of ANC visit & & & & & $<0.001$ \\
\hline None & $89(8.1)$ & $66(74.2)$ & $23(2.3)$ & 1 & \\
\hline 1 & $90(8.2)$ & $18(20.2)$ & $72(7.2)$ & $0.17(0.1$ to 0.29$)$ & \\
\hline 2 & $155(14.2)$ & $1(1.1)$ & $154(15.3)$ & $0(0$ to 0.03$)$ & \\
\hline 3 & $244(22.3)$ & $3(3.4)$ & $241(24.0)$ & 0.01 (0 to 0.03$)$ & \\
\hline $4+$ & $517(47.2)$ & $1(1.1)$ & $516(51.3)$ & $0(0$ to 0.01$)$ & \\
\hline Missing & 39 & 0 & 39 & & \\
\hline IPTp doses (HIV negative) & & & & & $<0.001$ \\
\hline None & $242(28.3)$ & $73(98.7)$ & 169 (21.7) & 1 & \\
\hline 1 & $95(11.1)$ & $1(1.4)$ & $94(12.1)$ & $0.04(0.01$ to 0.31$)$ & \\
\hline 2 & $175(20.5)$ & 0 & $175(22.4)$ & $0(0$ to 0$)$ & \\
\hline 3 & $222(26.0)$ & 0 & $222(28.5)$ & 0 (0 to 0$)$ & \\
\hline 4 & $120(14.1)$ & 0 & $120(15.4)$ & $0(0$ to 0$)$ & \\
\hline Missing & 280 & 18 & 265 & $0(0$ to 0$)$ & \\
\hline
\end{tabular}


Table 1 Continued

\begin{tabular}{|c|c|c|c|c|c|}
\hline & Overall ( $N=1134)$ & $\begin{array}{l}\text { Miscarriage } \\
(\mathrm{N}=89)\end{array}$ & $\begin{array}{l}\text { Other } \\
\text { pregnancy } \\
\text { outcomes } \\
(n=1045)\end{array}$ & HR (95\% Cl) & p Values \\
\hline Vaginal bleeding & & & & & $<0.001$ \\
\hline No & $813(97.3)$ & $14(77.8)$ & 799 (97.7) & 1 & \\
\hline Yes & $23(2.8)$ & $4(22.2)$ & $19(2.3)$ & 11.57 (4 to 33.46 ) & \\
\hline Missing & 298 & 71 & 227 & & \\
\hline \multicolumn{6}{|l|}{ ANC profile at first ANC visit } \\
\hline HIV positive & & & & & $<0.001$ \\
\hline Negative & $771(68.0)$ & $17(19.0)$ & 754 (72.2) & 1 & \\
\hline Positive & $262(23.1)$ & 27 (30.3) & $235(22.5)$ & 4.83 (2.62 to 8.9$)$ & \\
\hline Unknown & $101(8.9)$ & $45(50.6)$ & $56(5.4)$ & 25.83 (14.7 to 45.39$)$ & \\
\hline $\mathrm{Hb}$ (mean (SD; range)) & $11.2(1.9 ; 4.3-17.2)$ & $12.4(1.9)$ & $11.2(1.9)$ & $1.31(1.05$ to 1.63$)$ & 0.017 \\
\hline & Missing $n=309$ & Missing $n=72$ & Missing $n=237$ & & \\
\hline Anaemia $(\mathrm{Hb}<11 \mathrm{~g} / \mathrm{dL})$ & & & & & 0.184 \\
\hline No & $476(57.7)$ & $13(76.5)$ & $463(57.3)$ & 1 & \\
\hline Yes & 349 (42.3) & $4(23.5)$ & 345 (42.7) & $0.47(0.15$ to 1.44$)$ & \\
\hline Missing & 309 & 72 & 237 & & \\
\hline Syphilis reactive test & & & & & 0.750 \\
\hline Negative & 838 (92.3) & $20(95.2)$ & $818(92.2)$ & 1 & \\
\hline Positive & $70(7.7)$ & $1(4.8)$ & $69(7.8)$ & 0.79 (0.18 to 3.47$)$ & \\
\hline Missing & 226 & 68 & 158 & & \\
\hline $\begin{array}{l}\text { Malaria slide positive at first ANC } \\
\text { visit }\end{array}$ & & & & & 0.651 \\
\hline Negative & $712(86.0)$ & 16 (88.9) & $696(85.9)$ & 1 & \\
\hline Positive & $116(14.0)$ & $2(11.1)$ & $114(14.1)$ & 0.63 (0.09 to 4.61$)$ & \\
\hline Missing & 306 & 71 & 235 & & \\
\hline
\end{tabular}

probability of miscarriage calculated through the life table method was $18.9 \%$. Overall, the rate of miscarriage was 0.59 per 100 pregnancy-weeks ( $95 \%$ CI 0.47 to 0.73 ) calculated by survival analysis with left truncation. The weekly miscarriage rate declined steadily with increasing gestation (see figure 3 and table 2 for miscarriage

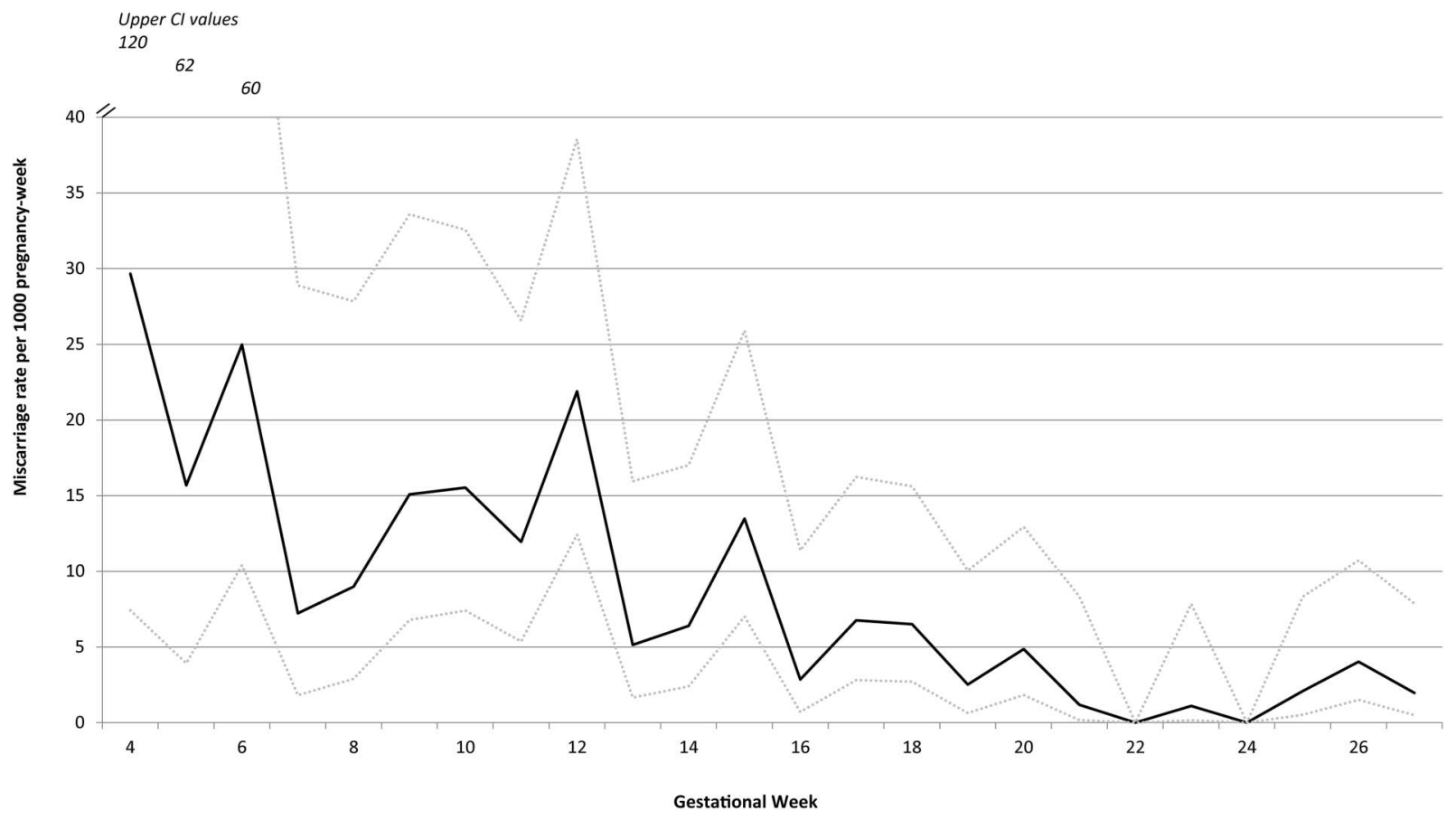

Figure 3 Miscarriage rate per 1000 pregnancy-week by week of gestation with upper and lower estimates of $95 \% \mathrm{Cl}$. 


\begin{tabular}{|c|c|c|c|c|c|c|c|c|c|c|c|}
\hline $\begin{array}{l}\text { Gestational } \\
\text { week }\end{array}$ & $\begin{array}{l}\text { Pregnancies } \\
\text { detected } \\
\text { during week }\end{array}$ & $\begin{array}{l}\text { Pregnancy- } \\
\text { weeks at } \\
\text { risk }\end{array}$ & Miscarriage & $\begin{array}{l}\text { Induced } \\
\text { abortion }\end{array}$ & $\begin{array}{l}\text { Loss to } \\
\text { follow-up } \\
\text { and } \\
\text { withdrawals }\end{array}$ & $\begin{array}{l}\text { Weekly miscarriage } \\
\text { rate per } 1000 \\
\text { pregnancy-weeks } \\
(95 \% \mathrm{Cl})\end{array}$ & $\begin{array}{l}\text { Probability of } \\
\text { miscarriage } \\
\text { per } \\
\text { gestational } \\
\text { week }\end{array}$ & $\begin{array}{l}\text { Probability of } \\
\text { survival per } \\
\text { gestational } \\
\text { week }\end{array}$ & $\begin{array}{l}\text { Cumulative } \\
\text { probability } \\
\text { of survival }\end{array}$ & $\begin{array}{l}\text { Cumulative } \\
\text { probability of } \\
\text { miscarriage }\end{array}$ & $\begin{array}{l}\text { Remaining } \\
\text { probability of } \\
\text { miscarriage }\end{array}$ \\
\hline$<4$ & 48 & 32.3 & 0 & 1 & 1 & 0 & 0.000 & 1.000 & 1.000 & 0.000 & 0.189 \\
\hline 4 & 42 & 67.4 & 2 & 0 & 0 & 29.66 (7.42 to 120$)$ & 0.029 & 0.971 & 0.971 & 0.029 & 0.189 \\
\hline 5 & 77 & 127.6 & 2 & 0 & 0 & 15.68 (3.92 to 62.69$)$ & 0.016 & 0.984 & 0.956 & 0.044 & 0.165 \\
\hline 6 & 79 & 200.1 & 5 & 0 & 0 & 24.98 (10.4 to 60.02$)$ & 0.025 & 0.975 & 0.932 & 0.068 & 0.152 \\
\hline 7 & 69 & 276.9 & 2 & 3 & 0 & 7.22 (1.81 to 28.88$)$ & 0.007 & 0.993 & 0.925 & 0.075 & 0.130 \\
\hline 8 & 71 & 334.1 & 3 & 1 & 1 & 8.98 (2.9 to 27.84$)$ & 0.009 & 0.991 & 0.917 & 0.083 & 0.124 \\
\hline 9 & 63 & 397.7 & 6 & 0 & 0 & 15.09 (6.78 to 33.58$)$ & 0.015 & 0.985 & 0.903 & 0.097 & 0.116 \\
\hline 10 & 59 & 451 & 7 & 0 & 0 & 15.52 (7.4 to 32.56$)$ & 0.015 & 0.985 & 0.889 & 0.111 & 0.103 \\
\hline 11 & 57 & 502.6 & 6 & 1 & 1 & 11.94 (5.36 to 26.57 ) & 0.012 & 0.988 & 0.879 & 0.121 & 0.088 \\
\hline 12 & 52 & 548.3 & 12 & 1 & 1 & $21.89(12.43$ to 38.54$)$ & 0.022 & 0.978 & 0.860 & 0.140 & 0.078 \\
\hline 13 & 41 & 583.4 & 3 & 1 & 0 & $5.14(1.66$ to 15.94$)$ & 0.005 & 0.995 & 0.855 & 0.145 & 0.057 \\
\hline 14 & 52 & 626.6 & 4 & 0 & 1 & $6.38(2.4$ to 17.01$)$ & 0.006 & 0.994 & 0.850 & 0.150 & 0.052 \\
\hline 15 & 40 & 667.9 & 9 & 0 & 0 & 13.47 (7.01 to 25.9$)$ & 0.013 & 0.987 & 0.839 & 0.161 & 0.046 \\
\hline 16 & 43 & 703.1 & 2 & 0 & 0 & 2.84 (0.71 to 11.37$)$ & 0.003 & 0.997 & 0.836 & 0.164 & 0.033 \\
\hline 17 & 44 & 739.9 & 5 & 1 & 0 & $6.76(2.81$ to 16.24$)$ & 0.007 & 0.993 & 0.831 & 0.169 & 0.030 \\
\hline 18 & 30 & 769.1 & 5 & 0 & 0 & 6.5 (2.71 to 15.62$)$ & 0.006 & 0.994 & 0.825 & 0.175 & 0.024 \\
\hline 19 & 33 & 796.4 & 2 & 0 & 0 & 2.51 (0.63 to 10.04$)$ & 0.003 & 0.997 & 0.823 & 0.177 & 0.018 \\
\hline 20 & 26 & 823.9 & 4 & 0 & 1 & $4.86(1.82$ to 12.94$)$ & 0.005 & 0.995 & 0.819 & 0.181 & 0.015 \\
\hline 21 & 33 & 852.1 & 1 & 0 & 1 & $1.17(0.17$ to 8.33$)$ & 0.001 & 0.999 & 0.818 & 0.182 & 0.010 \\
\hline 22 & 23 & 873.4 & 0 & 0 & 1 & 0 & 0.000 & 1.000 & 0.818 & 0.182 & 0.009 \\
\hline 23 & 36 & 905.6 & 1 & 0 & 0 & $1.1(0.16$ to 7.84$)$ & 0.001 & 0.999 & 0.817 & 0.183 & 0.009 \\
\hline 24 & 30 & 937.3 & 0 & 0 & 0 & 0 & 0.000 & 1.000 & 0.817 & 0.183 & 0.008 \\
\hline 25 & 20 & 960.1 & 2 & 0 & 0 & 2.08 (0.52 to 8.33$)$ & 0.002 & 0.998 & 0.816 & 0.184 & 0.008 \\
\hline 26 & 38 & 994.4 & 4 & 0 & 0 & 4.02 (1.51 to 10.72$)$ & 0.004 & 0.996 & 0.812 & 0.188 & 0.006 \\
\hline 27 & 28 & 1016.9 & 2 & 0 & 12 & 1.97 (0.49 to 7.86$)$ & 0.002 & 0.998 & 0.811 & 0.189 & 0.002 \\
\hline
\end{tabular}




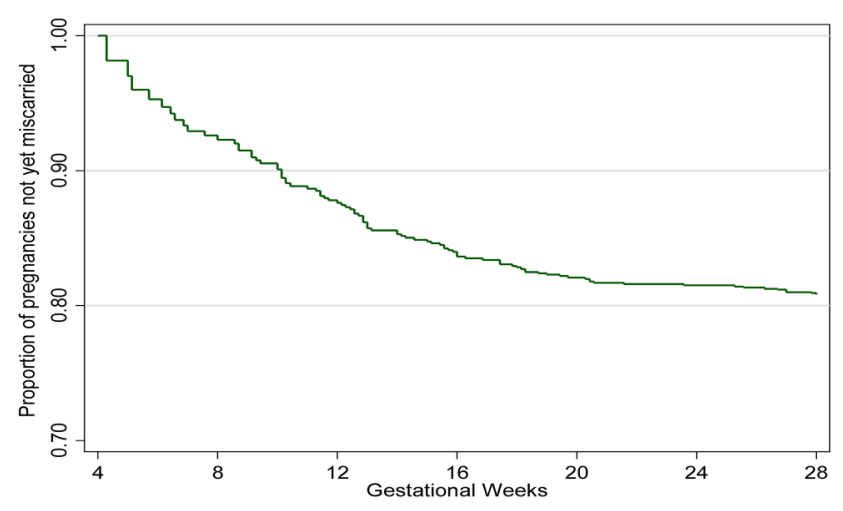

Figure 4 Miscarriage Kaplan-Meier survival curve by gestational week.

weekly rates and probabilities) until approximately 16-20 weeks, after which it remained steady at approximately 0.3 per 100 pregnancy-weeks. Figure 4 shows the cumulative pregnancy survival probabilities per gestation week.

\section{DISCUSSION}

This study provides the first description of the miscarriage rate in this rural Kenyan population in the context of high malaria and HIV prevalence; there are very little data on miscarriage background rate for sub-Saharan Africa in general. The cumulative probability of miscarriages by 28 weeks gestation accounting for a staggered pregnancy detection in our study population was $18.9 \%$, and the probability by week declined from 16 weeks onward. The true rate is likely to be higher as information from very early pregnancies (eg, <6 weeks gestation) was not captured and the average gestational age of pregnancy detection was 13.3 weeks, which meant that only $57 \%$ of pregnancies were detected during the highest risk period for miscarriage (the first trimester). However, this represents a more accurate estimate of the risk of miscarriage than the crude prevalence of $7.9 \%$ as pregnancies were not observed from the time of conception and entered the study at different gestational ages. $^{61015}$ The rate of $19 \%$ is similar to that reported by McGready et $a l^{39}$ from the Thai-Burmese border (20\%) and consistent with that observed in other prospective studies in non-malarious areas, which ranges from $10 \%$ to $22 \%$. Known risk factors for miscarriages were confirmed in this population, including older maternal age ${ }^{40}$ more than three previous pregnancies, ${ }^{41}$ having a previous pregnancy loss, ${ }^{42}$ HIV infection, ${ }^{43} 44$ occupation $^{23}$ and lower household wealth. ${ }^{45}$

Acceptability of pregnancy testing was surprisingly high and refusal to take a pregnancy test following enrolment remained around $2 \%$ throughout the homebased surveys. Women in this setting are usually reluctant to disclose their pregnancy status due to cultural and superstitious beliefs about pregnancy disclosure. This has been recognised as one of the reasons for delay in seeking ANC. ${ }^{19}{ }^{21}$ Women are worried about gossip, witchcraft (particularly in the early stage of pregnancy), being accused of boastfulness and embarrassment in case of later pregnancy loss. For unmarried and/or young girls, pregnancy is not disclosed due to fear of social repercussions. Before initiation of the study, no information was available on the acceptability of pregnancy tests in a similar rural community; our formative research indicated that very few women were even aware that such tests existed. In this community, engaging trained village-based staff to offer pregnancy tests through regular home visits worked well, as reflected by the high acceptance rate $(94 \%)$ and low loss to follow-up $(8 \%)$. Since the initiation of this study, other studies have used trained fieldworkers (both male and female) to do pregnancy detection and reported similar success. For future studies of miscarriage, we recommend working with the community to identify the most suitable approach to identify early pregnancy. Community health workers now being deployed in many sub-Saharan African countries ${ }^{46}$ could play a key role in early pregnancy detection, thus providing better data on the actual number of pregnancies for programmatic planning and monitoring as well as referring pregnant women to initiate ANC in the first trimester.

A few limitations should be noted. Despite our best efforts to capture pregnancy early, the relatively low numbers of pregnancy detected before 12 weeks gestation (508) generate moderately imprecise estimates and wide CIs particularly in early ( $<6$ weeks) gestation. Depending on the gestational age ascertainment method used, there could have been more or less measurement error leading to misclassification of the time at entry and exit in the cohort and, therefore, miscarriage rate in a specific gestation week. There could have been error in the estimation of gestation at the time of miscarriage since this was largely self-reported, sometimes months after the event. There is risk that induced abortions were misclassified as miscarriage or as lost to follow-up. Kenya has strict laws on induced abortion, and it is only permitted if, according to a trained health professional, there is a need for emergency treatment, or the life or health of the mother is in danger, or if permitted by any other written law. Owing to restrictive laws and stigmatisation, underreporting is common. Nine induced abortions $(<1 \%)$ were reported in this study, which is much lower than a reported expected ratio of 30 abortions per 100 births for Kenya. ${ }^{47}$ However, it is probable that women consenting to participate in the study would be at lower risk of seeking induced abortion by accepting to be followed up through pregnancy. This could lead to selection bias but the refusal rate was low at $5 \%$, and therefore this is unlikely to affect estimates substantially. Lastly, as HIV and malaria are known risk factors for miscarriage $^{39434448}$ and are highly prevalent in this area, this may influence the generalisability of study findings to areas with different disease burden. 


\section{CONCLUSION}

This prospective cohort study in WOCBA provides the first estimates of weekly miscarriage rates in a rural African setting in the context of high HIV and malaria prevalence. This information should be valuable to researchers and programme managers for resource planning, to monitor trends and impacts of interventions as well as to clinicians in gauging miscarriage rates at a given gestational week. We have demonstrated the feasibility of conducting a community-based pregnancy cohort in a resource-constrained setting for analysing the outcome of pregnancies with respect to miscarriage risk.

\section{Author affiliations \\ ${ }^{1}$ Liverpool School of Tropical Medicine, Liverpool, UK \\ ${ }^{2}$ Kenya Medical Research Institute Centre for Global Health Research, Kisumu, Kenya \\ ${ }^{3}$ Centers for Disease Control and Prevention, Atlanta, Georgia, USA \\ ${ }^{4}$ Global Health Institute, Emory University, Atlanta, Georgia, USA \\ ${ }^{5}$ Pharmacy Systems, Outcomes and Policy Department, University of Illinois at Chicago, Chicago, Illinois, USA \\ ${ }^{6}$ Departments of Pharmacy and Global Health, Schools of Pharmacy and \\ Public Health, University of Washington, Seattle, Washington, USA}

Acknowledgements The work presented in this paper was performed under the KEMRI and CDC Collaboration in western Kenya. The authors are very grateful to all participants for taking part in the study. They wish to thank the EMEP study team for their perseverance and hard work, particularly: Jane Oiro, Teresa Aluoch, Elizabeth Aballa, Emily Ayanga, Everlyne Oteyo, Everline Ochola, Faith Samo, Eric Onyango and Joshua Auko. Furthermore, the authors wish to thank the Asembo District health and medical team and the Lwak Mission Hospital Board for their support. They also wish to thank Dr. John Williamson and Jane Bruce for the statistical support and advice. KEMRI-CDC HDSS is a member of the INDEPTH Network. The findings and conclusions in this paper are those of the authors and do not necessarily represent the views of the US Centers for Disease Control and Prevention. This paper is published with the permission of the KEMRI Director.

Contributors SD, FOtK, AS, LS and MJH conceived and designed the experiments. SD, GA, PO, MO and GB conducted field work. SD and GC analysed the data. GB, DF, RFB, SK, DCB, NY, FO and FOtK contributed data/ analysis tools. SD, DCB, RFB, MJH, LS, DF, SK, KFL, AS, MD and FOtK interpreted the data. SD, FOtK and MD wrote the first draft of the manuscript. All authors reviewed, revised and approved the final version of the manuscript.

Funding This work was partly supported by the Malaria in Pregnancy (MiP) Consortium, which is funded through a grant from the Bill and Melinda Gates Foundation to the Liverpool School of Tropical Medicine, UK and partly by the US Centers for Disease Control and Prevention (CDC), Division of Parasitic Diseases and Malaria through a cooperative agreement with Kenya Medical Research Institute (KEMRI), Center for Global Health Research (CGHR), Kisumu, Kenya.

Disclaimer The findings and conclusions in this paper are those of the authors and do not necessarily represent the views of the US Centers for Disease Control and Prevention.

Competing interests None declared.

Ethics approval The study was reviewed and approved by the Institutional Review Boards of CDC (No. 5889), KEMRI (No. 1752) and the Liverpool School of Tropical Medicine (No. 09.70).

Provenance and peer review Not commissioned; externally peer reviewed.

Data sharing statement The anonymised data set will be available on request from the data manager at KEMRI: vwere@kemricdc.org.
Open Access This is an Open Access article distributed in accordance with the Creative Commons Attribution Non Commercial (CC BY-NC 4.0) license, which permits others to distribute, remix, adapt, build upon this work noncommercially, and license their derivative works on different terms, provided the original work is properly cited and the use is non-commercial. See: http:// creativecommons.org/licenses/by-nc/4.0/

\section{REFERENCES}

1. Goldstein DJ, Sundell KL, DeBrota DJ, et al. Determination of pregnancy outcome risk rates after exposure to an intervention. Clin Pharmacol Ther 2001;69:7-13.

2. Kline JK. Maternal occupation: effects on spontaneous abortions and malformations. Occup Med 1986;1:381-403.

3. Kumar S. Occupational, environmental and lifestyle factors associated with spontaneous abortion. Reprod Sci 2011;18: 915-30.

4. Millennium Development Goals Indicators. http://mdgs.un.org/unsd/ $\mathrm{mdg} /$ Metadata.aspx? Indicatorld=0\&Seriesld $=762$

5. World Health Organization. Reproductive health indicators: guidelines for their generation, interpretation and analysis for global monitoring. Geneva: World Health Organization, 2006.

6. Ammon Avalos L, Galindo C, Li DK. A systematic review to calculate background miscarriage rates using life table analysis. Birth Defects Res Part A Clin Mol Teratol 2012;94:417-23.

7. Wilcox AJ, Weinberg CR, O'Connor JF, et al. Incidence of early loss of pregnancy. N Engl J Med 1988;319:189-94.

8. Zinaman MJ, Clegg ED, Brown CC, et al. Estimates of human fertility and pregnancy loss. Fertil Steril 1996;65:503-9.

9. Ellish NJ, Saboda K, O'Connor J, et al. A prospective study of early pregnancy loss. Hum Reprod 1996;11:406-12.

10. Modvig J, Schmidt L, Damsgaard MT. Measurement of total risk of spontaneous abortion: the virtue of conditional risk estimation. Am J Epidemiol 1990;132:1021-38.

11. Wang $\mathrm{X}$, Chen $\mathrm{C}$, Wang $\mathrm{L}$, et al. Conception, early pregnancy loss, and time to clinical pregnancy: a population-based prospective study. Fertil Steril 2003;79:577-84.

12. Eskenazi B, Gold EB, Lasley BL, et al. Prospective monitoring of early fetal loss and clinical spontaneous abortion among female semiconductor workers. Am J Ind Med 1995;28:833-46.

13. Sweeney AM, Meyer MR, Aarons $\mathrm{JH}$, et al. Evaluation of methods for the prospective identification of early fetal losses in environmental epidemiology studies. Am J Epidemiol 1988; $127: 843-50$

14. Singh S, Sedgh G, Hussain R. Unintended pregnancy: worldwide levels, trends, and outcomes. Stud Fam Plann 2010;41:241-50.

15. Goldhaber MK, Fireman BH. The fetal life table revisited: spontaneous abortion rates in three Kaiser Permanente cohorts. Epidemiology 1991;2:33-9.

16. Mukherjee S. Timing of gestational arrest prior to miscarriage. Nashville, Tennessee: Vanderbilt University, 2014.

17. Central Statistical Agency [Ethiopia], ICF International. Ethiopia Demographic and Health Survey 2011. Calverton, Maryland: Central Statistical Agency, Addis Ababa, Ethiopia, ICF International Calverton, 2012

18. Ghana Statistical Service (GSS), Ghana Health Service (GHS), ICF Macro. Ghana Demographic and Health Survey 2008. GSS, GHS, Accra, Ghana. Calverton, Maryland: ICF Macro, 2009.

19. Pell C, Meñaca $A$, Were $F$, et al. Factors affecting antenatal care attendance: results from qualitative studies in Ghana, Kenya and Malawi. PLoS ONE 2013;8:e53747.

20. Haws RA, Mashasi I, Mrisho M, et al. These are not good things for other people to know: how rural Tanzanian women's experiences of pregnancy loss and early neonatal death may impact survey data quality. Soc Sci Med 2010;71(10):1764-72.

21. Stokes E, Dumbaya I, Owens S, et al. The right to remain silent: a qualitative study of the medical and social ramifications of pregnancy disclosure for Gambian women. BJOG 2008;115 (13):1641-7; discussion 1647.

22. Verhoeff FH, Milligan P, Brabin BJ, et al. Gestational age assessment by nurses in a developing country using the Ballard method, external criteria only. Ann Trop Paediatr 1997;17:333-42.

23. White LJ, Lee SJ, Stepniewska K, et al. Estimation of gestational age from fundal height: a solution for resource-poor settings. $J R$ Soc Interface 2012;9:503-10.

24. Dellicour S, Desai M, Aol G, et al. Risks of miscarriage and inadvertent exposure to artemisinin derivatives in the first trimester of pregnancy: a prospective cohort study in western Kenya. Malar $J$ 2015;14:461. 
25. Odhiambo FO, Laserson KF, Sewe M, et al. Profile: the KEMRI/CDC Health and Demographic Surveillance System-Western Kenya. Int J Epidemiol 2012;41:977-87.

26. Kenya National Bureau of Statistics (KNBS) and ICF Macro. Kenya Demographic and Health Survey 2008-09. Calverton, Maryland, USA, 2011. http://www.measuredhs.com/pubs/pdf/FR229/FR229.pdf.

27. Kenya National Bureau of Statistics (KNBS), Macro I. Kenya Demographic and Health Survey 2008-09. ICF Macro. Calverton, Maryland, 2010.

28. Dellicour S, Desai M, Mason L, et al. Exploring risk perception and attitudes to miscarriage and congenital anomaly in rural Western Kenya. PLoS ONE 2013;8:e80551.

29. Mason L, Dellicour S, Ter Kuile F, et al. Barriers and facilitators to antenatal and delivery care in western Kenya: a qualitative study. BMC Pregnancy Childbirth 2015;15:26.

30. Bigogo G, Audi A, Aura B, et al. Health-seeking patterns among participants of population-based morbidity surveillance in rural western Kenya: implications for calculating disease rates. Int $J$ Infect Dis 2010;14:e967-73.

31. Feikin DR, Audi A, Olack B, et al. Evaluation of the optimal recal period for disease symptoms in home-based morbidity surveillance in rural and urban Kenya. Int J Epidemiol 2010;39:450-8.

32. Ballard JL, Khoury JC, Wedig K, et al. New Ballard Score, expanded to include extremely premature infants. J Pediatr 1991;119:417-23.

33. McKenzie D. Measuring inequality with asset indicators. J Popul Econ 2005;18:229.

34. World Health Organization. Spontaneous and induced abortion: report of a WHO scientific group. WHO Technical Report Series. Vol. 461. Geneva, 1970

35. Regan L, Rai R. Epidemiology and the medical causes of miscarriage. Baillieres Best Pract Res Clin Obstet Gynaecol 2000;14:839-54.

36. Howards PP, Hertz-Picciotto I, Poole C. Conditions for bias from differential left truncation. Am J Epidemiol 2007;165:444-52.

37. Margulis AV, Mittleman MA, Glynn RJ, et al. Effects of gestational age at enrollment in pregnancy exposure registries. Pharmacoepidemiol Drug Saf 2015;24:343-52.
38. Meister R, Schaefer C. Statistical methods for estimating the probability of spontaneous abortion in observational studiesanalyzing pregnancies exposed to coumarin derivatives. Reprod Toxicol 2008;26:31-5.

39. McGready R, Lee SJ, Wiladphaingern J, et al. Adverse effects of falciparum and vivax malaria and the safety of antimalarial treatment in early pregnancy: a population-based study. Lancet Infect Dis 2012;12:388-96.

40. Smith KE, Buyalos RP. The profound impact of patient age on pregnancy outcome after early detection of fetal cardiac activity. Fertil Steril 1996;65:35-40.

41. Kline J. I. An epidemiological review of the role of gravidity in spontaneous abortion. Early Hum Dev 1978;1:337-44.

42. Regan L, Braude PR, Trembath PL. Influence of past reproductive performance on risk of spontaneous abortion. BMJ 1989;299: 541-5.

43. Brocklehurst $\mathrm{P}$, French $\mathrm{R}$. The association between maternal HIV infection and perinatal outcome: a systematic review of the literature and meta-analysis. Br J Obstet Gynaecol 1998;105: 836-48.

44. Temmerman M, Lopita MI, Sanghvi HC, et al. The role of maternal syphilis, gonorrhoea and HIV-1 infections in spontaneous abortion. Int J STD AIDS 1992;3:418-22.

45. Norsker FN, Espenhain L, A Rogvi S, et al. Socioeconomic position and the risk of spontaneous abortion: a study within the Danish National Birth Cohort. BMJ Open 2012;2:pii:e001077.

46. McCord GC, Liu A, Singh P. Deployment of community health workers across rural sub-Saharan Africa: financial considerations and operational assumptions. Bull World Health Organ 2013;91:244-253B.

47. African Population and Health Research Center, Ministry of Health Kenya. Ipas, Guttmacher Institute. Incidence and complications of unsafe abortion in Kenya: key findings of a national study. Nairobi, Kenya, 2013.

48. Desai M, ter Kuile FO, Nosten F, et al. Epidemiology and burden of malaria in pregnancy. Lancet Infect Dis 2007;7:93-104 